\title{
Trade Negotiation Capacity and Health Carve-Outs in Trade Agreements
}

\author{
Sheikh Shahnawaz \\ Department of Economics, California State University, Chico, CA 95929, USA \\ Correspondence should be addressed to Sheikh Shahnawaz; sheikh.shahnawaz@gmail.com
}

Received 28 April 2014; Accepted 16 July 2014; Published 23 July 2014

Academic Editor: David E. Giles

Copyright ( 2014 Sheikh Shahnawaz. This is an open access article distributed under the Creative Commons Attribution License, which permits unrestricted use, distribution, and reproduction in any medium, provided the original work is properly cited.

\begin{abstract}
There is a dearth of scholarship on the relationship between international trade and health status in countries. This paper contributes to filling this gap by proposing a formal analytical framework to study the link between the extent of health issues carved out from trade agreements by negotiating countries and their expenditure on public health. We also examine the role played by the nature of the political and fiscal regime prevalent in the country in the securing of the carve-outs. The model predicts that a higher level of carve-outs is more likely for countries that have relatively low levels of public health spending and which tend to be more politically free and fiscally liberal. We provide anecdotal evidence that supports our findings.
\end{abstract}

\section{Introduction}

There has been a long tradition in economics of examining the link between international trade and economic development and growth $[1,2]$. While most studies suggest a generally positive relationship between trade openness and growth of incomes, the link of openness with the various aspects of economic development appears more complicated $[3,4]$. Trade rules, in particular, seem to have the potential to constrain developing country governments to implement domestic policies that safeguard the health and well-being of their populations. For example, some recent trade agreements have focused on eliminating trade restrictions on tobacco products and have even gone as far as taking aim at regulations on the domestic advertising and distribution of these products in developing countries [5]. Another well-known concern is the impact of international trade rules on intellectual property and its implications for access to medicine-especially antiretroviral drugs to treat HIV/AIDS-in developing countries [6].

With the burgeoning interest in and importance of the mechanisms that drive trade policy as it relates to population health, there is a growing need for formal analytical frameworks to consider relevant issues rigorously. Some contributions toward this end include Shaffer et al.s [7], which provide a comprehensive discussion on the linkages between global trade and national health, and Blouin et al. [8], which outline a conceptual framework between liberalization and health outcomes with an emphasis on social determinants of health such as income and economic insecurity. More specific issue-oriented works include Kimball [9], which consider the challenges posed by emerging infectious diseases in a globalized world, and Shahnawaz [10], which examine the evolution of intellectual property-related trade policy in the wake of disease outbreaks.

There has been wide recognition of the disadvantage that developing countries have in negotiating global trade rules with usually more experienced and better resourced developed-country delegations and hence of the need for building developing country negotiation capacity [11, 12]. But there is an absence of formal analyses looking at such concerns and how these impinge on governments due to their need to pay attention to competing policy issues. This paper fills that gap by focusing on the relationship between government policies to prioritize the building of trade negotiation capacity as it pertains to public health and decisions regarding public health expenditure. Using a formal model, the paper proposes a link between optimal spending on developing negotiation capacity and public health expenditure and suggests that this link depends on the 
openness of the political regime as well as on the level of fiscal conservatism in the country's politics.

The paper is organized as follows: we start by presenting and solving the model in Section 2. In Section 3, we study the impact of changes in model parameters on the optimal value of government spending on negotiation capacity and put these results in context. Section 4 concludes by summarizing the analysis and discussing avenues for future research.

\section{The Model}

We analyze the decisions of a government whose objective is to maximize its own value function. It uses the levels of spending on public health at home and on developing trade negotiating capacity targeted to secure health carve-outs in trade agreements, to achieve this goal.

Let $H(g)$ be a function that captures the level of health carve-outs obtained when $g$ dollars are spent on developing the country's negotiating capacity. This function is well behaved in the sense that $H^{\prime}(g)>0$ and $H^{\prime \prime}(g)<0$. In addition, we assume, without loss of generality, that $H(0)=0$. Since there will be an upper limit to the level of carve-outs that can be secured by any party to a trade agreement, we also have

$$
\lim _{g \rightarrow \infty} H(g)=M, \quad \lim _{g \rightarrow \infty} H^{\prime}(g)=0,
$$

where $M>0$.

Let $X$ denote a measure of the public health status. For example, this could be the number of sick individuals in the country following the adoption of the trade agreement. This variable is random since its value is realized only after the government makes its expenditure decisions. However, policymakers know the distribution of $X$ to be given by

$$
f(x)=\frac{1}{H(g)} \varphi(H(g)-x),
$$

where

$$
\varphi(H(g)-x)= \begin{cases}0 & \text { if } H(g) \leq x \\ 1 & \text { if } H(g)>x\end{cases}
$$

We assume for simplicity that a unit of health carve-outs is smoothly converted to a unit of public health status (since nothing crucially depends on this).

Let $G$ be the minimum expenditure per sick person required to cure an individual. This means that if the government aims to cure $s$ sick individuals, then $s G$ is the total expenditure on public health. Curing each sick individual generates a benefit of $B$ dollars for the government. On the other hand, overspending on public health-measured by the difference between $s G$ and the minimum expenditure needed to cure the actual number of sick individualsimposes a political opportunity cost on the government, perhaps because the amount overspent could be diverted toward other public concerns. We denote this political cost by $\varepsilon$. Then the government's net political gain is given by

$$
\begin{aligned}
V= & B\{X+(s-X) \varphi(X-s)\} \\
& -G s-\varepsilon G(s-X) \varphi(X-s)-g .
\end{aligned}
$$

Since $X$ is unknown when policy decisions are made, the government maximizes its expected net political gains given by

$$
\begin{aligned}
E(V)= & B \int_{0}^{\infty}(x+(s-x) \varphi(s-x)) f(x) d x \\
& -G \varepsilon \int_{0}^{\infty}(s-x) \varphi(s-x) f(x) d x-s G-g .
\end{aligned}
$$

Hence, the optimal number of individuals, $s^{*}$, that the government commits to treat and which determines the optimal expenditure on public health is captured by

$$
\int_{0}^{s^{*}} f(x) d x=\frac{B-G}{B+\varepsilon G} H(g) .
$$

Now substituting (2) into (6), we get

$$
s^{*}(g)=\frac{B-G}{B+\varepsilon G} H(g) .
$$

Solving for the optimal expected political gain yields

$$
E(V)=\frac{(B-G)^{2}}{2(B+\varepsilon G)} H(g)-g .
$$

Since (8) is the maximum expected political gain for any $g$, we can now derive the optimal expenditure on developing negotiation capacity. The first order condition then gives

$$
H^{\prime}\left(g^{*}\right)=\frac{2(B+\varepsilon G)}{(B-G)^{2}},
$$

which can be written as

$$
g^{*}=F^{-1}(y),
$$

where $F(\cdot)=H^{\prime}(\cdot)$ and $y=2(B+\varepsilon G) /(B-G)^{2}$.

\section{Analysis and Discussion}

We can now use (10) to examine the impact of changes in costs and benefits on the optimal expenditure on developing negotiating capacity which is aimed at securing health carveouts. For what follows, we assume $B>G$; that is, we focus on the nontrivial case where the benefit to the government from curing a sick individual exceeds its cost. This does not necessarily mean that spending to cure a sick individual is always preferred since there are additional costs, such as the political costs of overspending described in the previous section, that have to be taken into account.

Comparative statics on $g^{*}$ then reveals

$$
\begin{aligned}
\frac{\partial g^{*}}{\partial G} & =\frac{2(\varepsilon(B+G)+2 B)}{(B-G)^{3}} F^{-1^{\prime}}(y)<0, \\
\frac{\partial g^{*}}{\partial B} & =\frac{-2(B+G(1+2 \varepsilon))}{(B-G)^{3}} F^{-1^{\prime}}(y)>0, \\
\frac{\partial g^{*}}{\partial \varepsilon} & =\frac{2 G}{(B-G)^{2}} F^{-1^{\prime}}(y)<0 .
\end{aligned}
$$

From (11) above, we see that the optimal expenditure on developing negotiation capacity, $g^{*}$, increases with 
(i) a decrease in public health expenditure, $G$,

(ii) an increase in the benefit from curing a sick individual, $B$,

(iii) a decrease in the political opportunity cost of overspending, $\varepsilon$.

The results suggest that spending on building negotiation capacity to secure health carve-outs in trade agreements is deemed less necessary by the government when policy is dedicated to enhance and maintain public health through high expenditure levels. Robust public health status could therefore make the government more willing to either not pursue carve-outs or use them to obtain trade concessions in other sectors from its potential trade partners. If the government attaches a higher value to curing a sick individual, it is likely to spend more on strengthening its negotiation capacity since any policy that contributes to superior health status would increase expected net political gains. Hence, we could observe this in countries where the political regime is either a benevolent dictatorship or it incorporates the will of the people in policymaking and is democratic.

More spending on negotiation capacity is also likely if the political opportunity cost of spending is low. This notion captures the importance to the government of efficiency in public spending. Conversely, if health levels are generally superior, high public health spending could suffer from the perception of being superfluous with funds being diverted from other pressing social needs. This could reduce the government's incentive to pursue policies that could lead to better overall health levels, having the paradoxical result of an anemic approach to securing health carve-outs in trade agreements. Countries where fiscal conservatism holds sway would be more likely to experience this outcome.

Although no database reports details on government spending to develop negotiation capacity, particularly as it relates to securing health carve-outs, we can discuss some anecdotal evidence on trade negotiations where health concerns played a role. One such case is Malaysia's proposal to exclude tobacco from the Trans Pacific Partnership trade agreement (TPP) to reduce smoking-related illnesses in participating nations. The tough stance in the ongoing negotiations is held in part as a reaction to a challenge from Philip Morris, which used intellectual property arguments (more on these below) to prevent Thailand and Uruguay from putting graphic health warnings on cigarette packs. Malaysia's efforts to carve out tobacco from the TPP are consistent with our model's predictions of a "free"-according to Freedom House-political regime, relatively low health expenditure (just under 4 percent of GDP), and government budgets in the red (as high as 6.1 percent of GDP in recent years).

Another recent example is Pakistan's experience with negotiations on the General Agreement on Trade in Services (GATS), part of the World Trade Organization (WTO) family of agreements that covers trade in health services. Significantly, Pakistan took a "public services carve-out" which protects publicly provided essential health services from foreign competition. This is seen by many public health professionals as an essential step to ensure affordable health care. Pakistan is graded by Freedom House as being "partly free" in terms of political rights and civil liberties. Together with the fact that the country hovers around 3 percent in terms of health expenditure to GDP and consistently runs sizeable budget deficits ( 8 percent in 2012), we see the predictions of the model validated to a large extent.

The signing by Jordan of a bilateral trade agreement with the US illustrates the case of significant health concessions made by the former. This agreement includes the so-called TRIPS-plus obligations, which up the ante on the strong patent regimes introduced by the WTO's Trade-Related Aspects of Intellectual Property Rights (TRIPS) agreement. The provisions of the TRIPS agreement impinge upon access to new and patented medicines and health-related technologies by constraining the ability of developing country governments to make these available to their populations. Jordan is therefore committed to abiding by the stringent rules of TRIPS-plus embedded in the US-Jordan Free Trade Agreement (FTA). Our analysis predicts a more authoritarian system of governance where countries readily give up health sector flexibilities, and this is in accordance with Jordan's rating by Freedom House as "not free" on political freedoms and civil liberties. The model also anticipates high levels of public health expenditure in these situations. For Jordan, spending on health as a percentage of GDP has rarely dipped below a strong 8.5 percent, which is comparable to countries like Sweden and Norway. Jordan runs relatively high budget deficits, which our model suggests should have been consistent with a stronger commitment to safeguarding TRIPS flexibilities. The government's acceptance of the TRIPS-plus provisions in its FTA could therefore be an indication that better measures for fiscal conservatism are needed as this research is taken forward.

The aforementioned cases provide some anecdotal support for our model and its predictions. While certainly not the final word, the cases provide some real-world evidence in the absence of more comprehensive data and serve as a first step toward a more rigorous empirical analysis of the proposed relationships between negotiation capacity and model parameters.

\section{Conclusion}

The shortage of formal models for understanding the relationship between trade policy strategy and domestic public health in trading countries is a gap in existing scholarship on the effects of globalization and health. This paper contributes to the filling of this gap by providing a formal analytical framework to study the evolution of policy toward developing trade negotiation capacity on issues related to health. The model is used to derive implications of the type of political and fiscal regime as well as of public health expenditure for a country's negotiation capacity. We find that a country is more likely to create negotiation capacity to secure health carveouts in trade agreements if its spending on public health is relatively low and if it is more democratic and fiscally liberal.

This area of research within international economics contains many opportunities to contribute to the body of knowledge. A start could be made by extending the framework proposed in this paper. For example, the effectiveness 
of negotiation capacity in securing carve-outs, assumed to be linearly related in this paper, could be modeled as a more nuanced link that depends on the level of concessions obtained up to that point in the negotiation process. Similarly, the model could be extended by modeling the connection between domestic health expenditure and public health status as a function of the specific health challenges faced by the country in question and its existing health status. Finally, the research community would benefit immensely from a database containing information on spending on the training and capacity building of trade delegations, the size of these delegations, and the issues trade negotiators negotiate about, some of which are discussed in [13]. Such a database would serve to deepen our empirical understanding of the relevant issues.

\section{Conflict of Interests}

The author declares that there is no conflict of interests regarding the publication of this paper.

\section{References}

[1] J. A. Frankel and D. Romer, "Does trade cause growth?" The American Economic Review, vol. 89, no. 3, pp. 379-399, 1999.

[2] D. A. Irwin and M. Terviö, "Does trade raise income?: Evidence from the twentieth century," Journal of International Economics, vol. 58, no. 1, pp. 1-18, 2002.

[3] D. Rodrik, The Globalization Paradox: Democracy and the Future of the World Economy, W. W. Norton, 2011.

[4] A. Deaton, "Health in an age of globalization," Brookings Trade Forum, pp. 83-130, 2004.

[5] E. R. Shaffer, J. E. Brenner, and T. P. Houston, "International trade agreements: a threat to tobacco control policy," Tobacco Control, vol. 14, supplement 2, pp. ii19-ii25, 2005.

[6] C. Fink and K. Maskus, Intellectual Property and Development: Lessons from Recent Economic Research, World Bank, 2005.

[7] E. R. Shaffer, H. Waitzkin, J. Brenner, and R. Jasso-Aguilar, "Global trade and public health," American Journal of Public Health, vol. 95, no. 1, pp. 23-34, 2005.

[8] C. Blouin, M. Chopra, and R. van der Hoeven, "Trade and social determinants of health," The Lancet, vol. 373, no. 9662, pp. 502507, 2009.

[9] A. Kimball, Risky Trade: Infectious Disease in the Era of Global Trade, Ashgate, 2006.

[10] S. Shahnawaz, "The optimal timing of compulsory licensing: a story of Thailand's winter of discontent," Global Economy Journal, vol. 12, no. 4, article 7, 2012.

[11] P. Drahos, "When the weak bargain with the strong: negotiations in the world trade organization," International Negotiation, vol. 8, no. 1, pp. 79-109, 2003.

[12] A. M. Pollock and D. Price, "The public health implications of world trade negotiations on the general agreement on trade in services and public services," The Lancet, vol. 362, no. 9389, pp. 1072-1075, 2003.

[13] K. Bagwell and R. W. Staiger, "What do trade negotiators negotiate about? Empirical evidence from the world trade organization," American Economic Review, vol. 101, no. 4, pp. 1238-1273, 2011. 

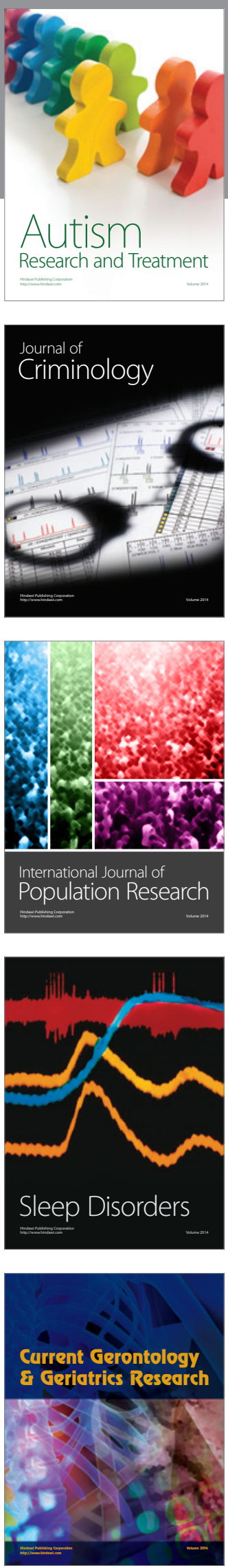
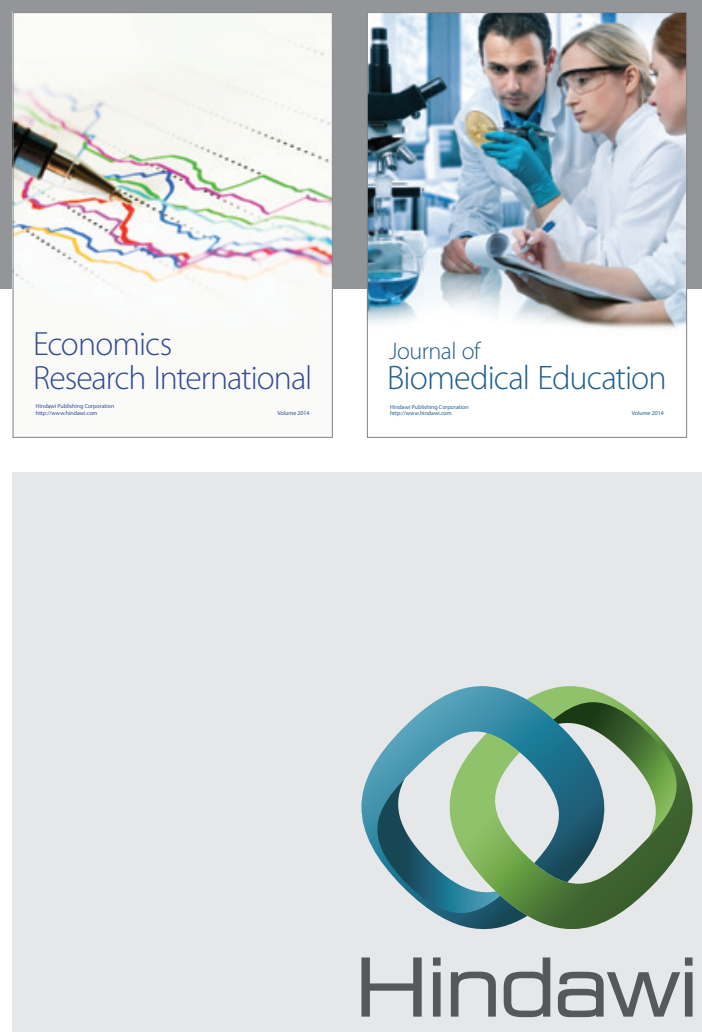

Submit your manuscripts at

http://www.hindawi.com
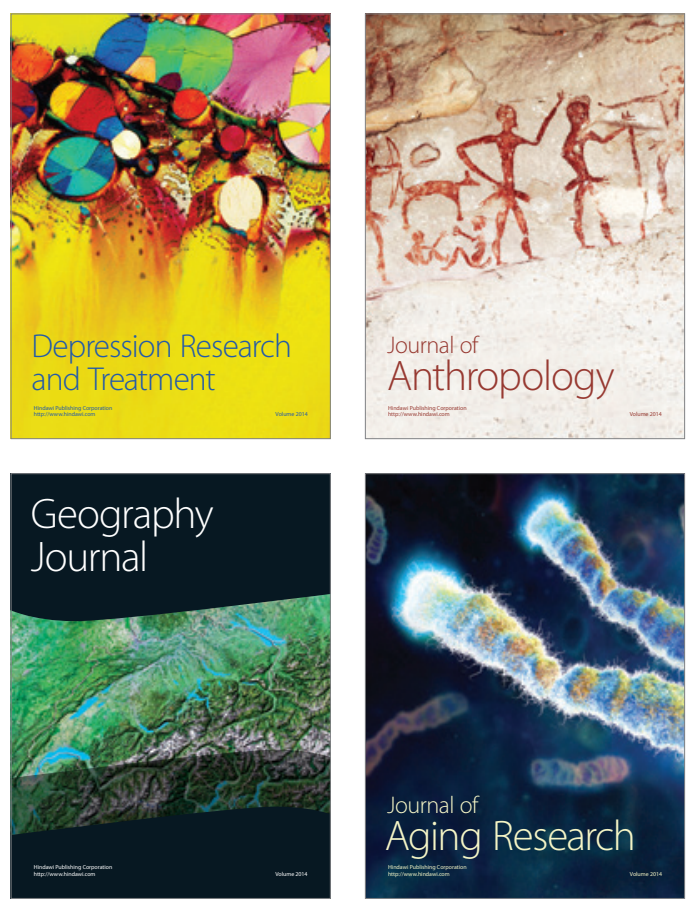
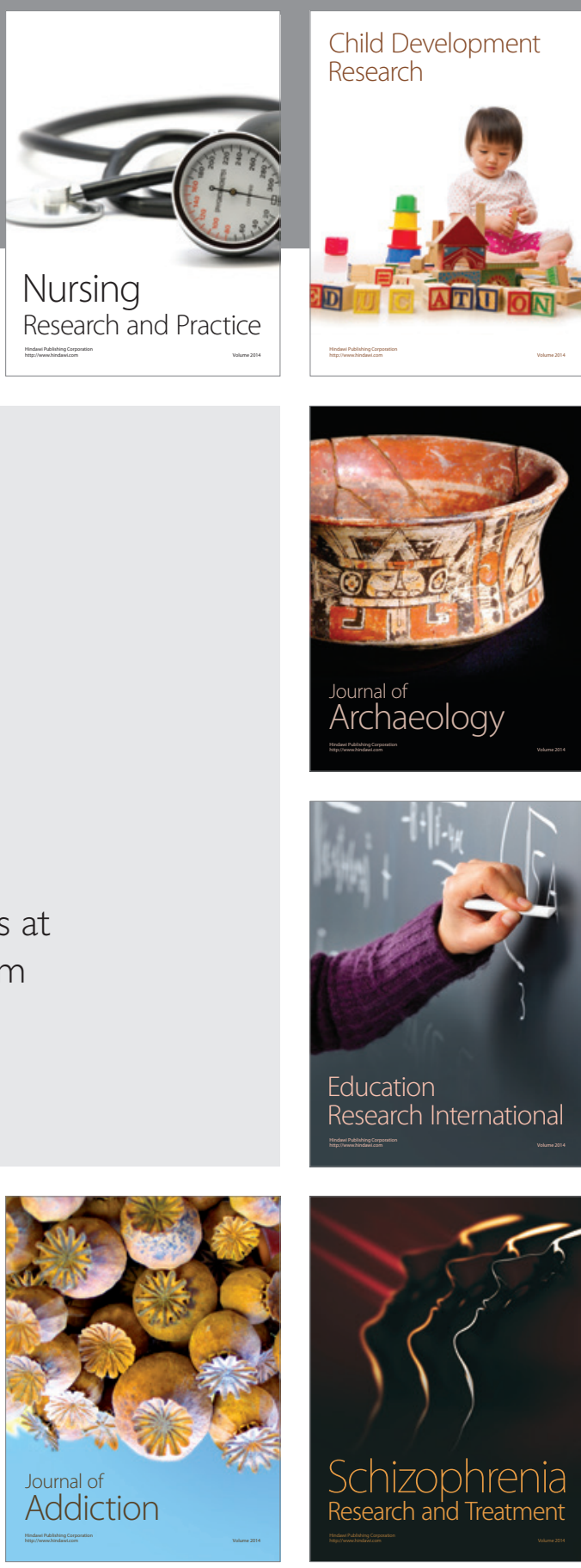

(D)
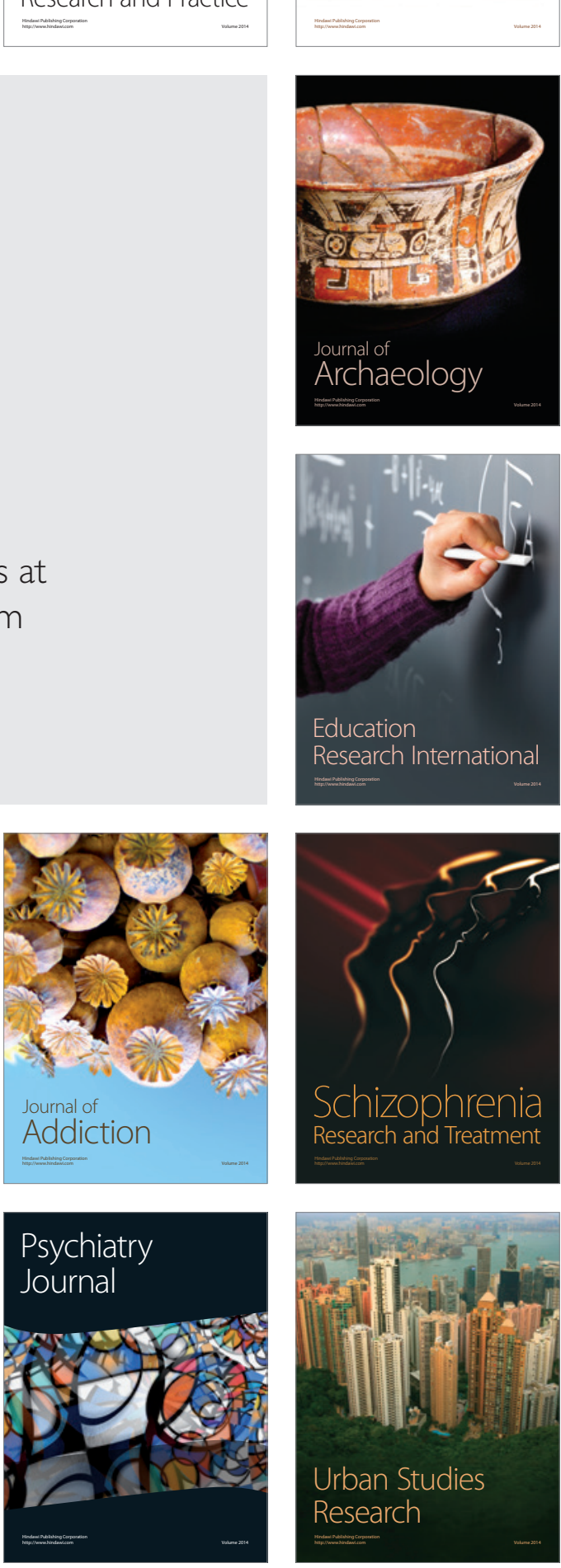